\title{
Cenas cotidianas: cultura de consumo e mídia em contos de André Sant'Anna
}

Ligia Bezerra $^{1}$

Um empresário dirigindo um carro vermelho importado em direção ao aeroporto, onde embarcará em um voo da American Airlines com destino a Nova York. Uma mulher que fala sobre a importância da aparência para homens e mulheres no que diz respeito à vida pessoal e profissional. Um produtor cultural que imagina um videoclipe superpós-moderno para a música supervanguarda de uma banda brasileira que ele promete promover. Uma diretora de televisão que explica como funciona a indústria de entretenimento, ressaltando que “televisão não é lugar para Glauber Rocha" (Sant'Anna, 2007, p. 85). Vários dos relatos de Sexo e amizade, do escritor brasileiro contemporâneo André Sant'Anna (2007), lidam com a presença da cultura de consumo na vida cotidiana brasileira. A primeira parte do livro, intitulada Amizade, reúne uma série de contos curtos, ou uma espécie de relatos, os quais podem ser lidos de maneira independente tanto entre si quanto em relação à segunda parte do livro, uma narrativa intitulada Sexo. Os diferentes pedaços do livro são conectados pelo foco no cotidiano de pessoas de várias classes sociais e por uma linguagem marcada por repetição, coloquialismos e clichês.

Neste trabalho, apresentamos uma análise da representação da cultura de massas e da cultura de consumo em quatro relatos dessa obra: "O importado vermelho de Noé", "Questão estética", "Cultura" e "O mundo é assim". Situamos essa obra de André Sant'Anna no fluxo de um extenso diálogo da literatura brasileira com a cultura de massas, o qual tem se efetivado desde o início do século XX, com o trabalho de modernistas como Oswald de Andrade, e através do qual a literatura brasileira tem, com frequência, elaborado uma crítica à cultura de consumo. Especialmente desde os anos 1960, a cultura de massas tem sido incorporada por escritores brasileiros, em geral de modo a criar uma "estética da dificuldade", como afirma a pesquisadora Lidia Santos em Tropical kitsch: media in Latin American literature and art (2006). Essa estética, segundo a autora, se caracteriza por um trabalho experimental

\footnotetext{
${ }^{1}$ Doutoranda em português e espanhol na Indiana University e professora-assistente no Spelman College, Georgia, Estados Unidos. E-mail: lbezerra@spelman.edu
} 
que tende a gerar textos compostos em uma linguagem de acesso relativamente difícil ao leitor. Tais textos, em geral, tematizam a cultura de massas como uma arma de alienação e representam a cultura de consumo como criadora de limites entre as camadas mais populares e as mais abastadas que habitam os grandes centros urbanos.

Desde os anos 1990 a literatura brasileira tem representado a cultura de massas e sua reprodução da cultura de consumo como parte integrante não apenas no cotidiano das camadas populares, mas também no dia a dia de uma classe média cujo consumo de bens materiais e culturais é cada vez mais marcado pela influência de uma cultura estrangeira, predominantemente americana, reterritorializada. Neste trabalho, argumentamos que Sant'Anna representa a cultura de consumo como uma força intrinsecamente presente nas relações sociais e na forma de pensar dos personagens. Afastando-se da estética da dificuldade a que se refere Santos, André Sant'Anna articula uma crítica da presença da cultura de consumo no cotidiano brasileiro a partir de uma linguagem predominantemente midiática e acessível, de forma não a afirmar, mas, sim, a questionar a influência da cultura de consumo e da cultura de massas sobre indivíduos oriundos de diferentes classes sociais.

\section{Cultura de massas, cultura de consumo e cotidiano}

Antes de passar à discussão dos contos, é importante definir brevemente os principais termos que guiam a presente análise: cultura de massas, cultura de consumo e cotidiano. O primeiro termo, cultura de massas, é geralmente entendido como um conjunto de produtos culturais direcionados ao consumo em massa e disseminados pela mídia, como programas de televisão, filmes, romances populares, música pop etc. $\mathrm{O}$ termo em questão é bastante complexo, especialmente dadas as múltiplas perspectivas com as quais ele tem sido tomado em posicionamentos teóricos distintos. Classicamente, a expressão cultura de massas tem conotações negativas, em grande parte em consequência da influência do trabalho de teóricos como o alemão Theodore Adorno, para quem a cultura de massas representa uma degradação da alta cultura, cujas influências alienantes sobre os sujeitos devem ser combatidas (Adorno, 1990). Por outro lado, pensadores como o francês Edgar Morin relativizam o termo ao apontar o fato de que a cultura de massas possibilita mais oportunidades de expressão da criatividade, embora o 
autor ressalve que a qualidade média de produtos da cultura de massas seja baixa (Morin, 1967). No que diz respeito ao pensamento latinoamericano, Jesús Martín-Barbero é uma das principais figuras que relativizam o termo ao defender que a cultura de massas não é uma degradação da alta cultura, mas, sim, uma forma de mediação entre classes sociais, possibilitada pela incorporação de elementos do gosto popular à cultura hegemônica (Martín-Barbero, 1993).

Para fins da análise dos contos de André Sant'Anna, tomamos a cultura de massas como a expressão de uma cultura predominantemente urbana na qual se fundem elementos das chamadas alta e baixa culturas de origem nacional e estrangeira, especialmente americana. A cultura de massas é vista aqui como uma cultura que atravessa diferentes classes sociais, promovendo o consumo das mais variadas mercadorias e criando um código que serve de base à percepção das relações sociais. Em outras palavras, a cultura de massas promove um consumo que não termina com a aquisição do produto em si, mas que perpassa toda uma forma de traduzir a realidade social em termos do que a aquisição desses produtos representa, conforme propõe o teórico Néstor García Canclini em Consumers as citizens: globalization and multicultural conflicts (2001). Neste estudo, Canclini define o termo consumo como "o conjunto de processos socioculturais nos quais se dá a apropriação e o uso de produtos" (Canclini, 2001, p. 38, tradução nossa). O crítico cultural em questão ressalta que, entendido desta forma, o consumo não se refere apenas ao resultado de diferenças de gosto ou de reflexões críticas acerca do poder de compra de cada consumidor. Tal definição de consumo, segundo o autor, considera que diferenças de classe social que se manifestam na produção de bens de consumo também se reproduzem no momento em que esses bens são consumidos. Em outras palavras, indivíduos de diferentes classes sociais têm acesso a diferentes bens de consumo e consomem em diferentes proporções. $O$ autor também aponta que o consumo na realidade não cria somente divisões em uma sociedade, mas gera também formas de integração na medida em que cria códigos de comunicação entre os indivíduos. Ou seja, bens de consumo adquirem certos significados simbólicos (de sofisticação ou de qualidade brega, por exemplo) porque os membros de uma mesma sociedade reconhecem tais significados. 
Nos contos de Sant'Anna que aqui analisamos, essas dinâmicas sociais do consumo e da cultura de massas aparecem retratadas a partir de duas perspectivas: a daqueles que consomem, no caso de "O importado vermelho de Noé" e "Questão estética", e a daqueles que produzem (cultura de massa em particular), foco principal de "Cultura" e "O mundo é assim". No caso dos dois primeiros, discutiremos em particular a delineação de status social a partir do consumo segundo a perspectiva dos protagonistas de cada relato em questão. No caso dos dois últimos contos, analisaremos como os relatos dos personagens principais deixam entrever relações entre alta e baixa culturas na produção cultural contemporânea dentro do contexto do capitalismo tardio.

Com relação ao terceiro termo relevante para nossa análise, cotidiano, há pelo menos duas formas de pensá-lo nos estudos culturais. Se, por um lado, existe uma tendência em se concordar em que uma das características principais do cotidiano é o seu caráter repetitivo, teóricos se dividem entre posições mais ou menos negativas ou positivas em relação a essa repetitividade. Aqueles que se filiam a tendências menos positivas enfatizam o caráter alienante dessa repetição, a qual levaria o indivíduo a não questionar as suas condições sociais. Tal alienação seria característica, segundo muitos dos pesquisadores em questão, de certos grupos ou classes sociais específicos, como as mulheres ou o trabalhador assalariado. Já os que se filiam às tendências mais positivas percebem que o cotidiano não tem um caráter exclusivamente repetitivo e que a repetição que o caracteriza pode ser interrompida por eventos que mudam o seu ritmo, instaurando novas configurações, novos ciclos de repetição. Em seu artigo "The invention of everyday life", a pesquisadora Rita Felski faz um apanhado dessas duas tendências e apresenta uma definição de cotidiano que procura atingir um equilíbrio entre essas duas posições. Ela define o termo como

um conjunto de atividades circunscritas no mundo. A vida cotidiana é o simples processo de se tornar acostumando a suposições, comportamentos e práticas que se tornam evidentes em si mesmas e são tidas como certas. Em outras palavras, a qualidade de ser cotidiano [everydayness] não é algo intrínseco que magicamente se adere a ações ou pessoas em particular [as mulheres, a classe trabalhadora]. Do contrário, o ser cotidiano é um processo vivo de rotinização que todos os indivíduos experimentam (Felski, 2000, p. 31, tradução nossa). 
A definição apresentada por Rita Felski, tomada emprestado da contribuição do filósofo francês Henri Lefebvre, ajuda-nos a compreender como a cultura de consumo e a cultura de massas são retratadas nos contos de André Sant'Anna em questão. Os relatos de Sant'Anna representam essas duas culturas como parte integrante da vida de indivíduos com diferentes tipos de background social: homens, mulheres, membros das classes alta e média, empresários, secretárias, produtores culturais, taxistas etc. Em outras palavras, a cultura de consumo aparece nos contos como algo corriqueiro, sua influência sendo revelada pela própria fala dos personagens, suas atitudes, a maneira como se vestem, os bens que possuem, e não pelo confronto de ideias entre diferentes personagens, ou por uma voz narrativa que guie a interpretação dos fatos. Esses retratos do cotidiano são captados de forma a dar a impressão de que estamos assistindo a uma cena, e não de que estamos lendo uma história. Assim sendo, Sant'Anna estabelece um diálogo com a cultura de massas e a cultura de consumo em seu texto não tanto de forma a criar uma estética da dificuldade, mas, sim, de reproduzir a linguagem da mídia sem, no entanto, fazê-lo de forma afirmativa. $\mathrm{O}$ resultado dessa abordagem são textos que, embora à primeira vista pareçam leves e sem profundidade, estabelecem uma crítica da presença intrínseca da cultura de massas e da cultura de consumo na vida cotidiana brasileira atual, como veremos na análise a seguir.

\section{Consumo e status social em "O importado vermelho de Noé" e "Questão estética"}

No primeiro conto a ser analisado, "O importado vermelho de Noé", acompanhamos um alto executivo dirigindo até o aeroporto, onde irá embarcar para Nova York. O conto é basicamente uma transcrição dos pensamentos (ou talvez de um monólogo) do personagem. A fala do protagonista revela uma compulsão com um discurso de sucesso pessoal e profissional, o qual ele acredita haver atingido. Servem de provas dessas conquistas os bens materiais que ele acumulou, bem como o acesso à cultura e capital americanos. O principal símbolo de seu poder de consumo é o carro que ele dirige ao aeroporto: um carro vermelho importado da Alemanha, ao qual insistentemente se refere e com o qual compara os "abjetos carros nacionais" (Sant'Anna, 2007, p. 14). $\mathrm{O}$ personagem tem consciência do status social que possuir e dirigir seu 
carro lhe confere. Como ele mesmo afirma, "enxergo claramente a diferença entre o meu carro vermelho, importado da Alemanha, e os carros nacionais. A diferença que me separa definitivamente dos pedestres que invadem a via onde trafega o meu carro vermelho, importado da Alemanha" (Sant'Anna, 2007, p. 10).

O carro que o personagem caracteriza como perfeito e veloz não só o distingue socialmente, mas o separa fisicamente de indivíduos de outras camadas sociais. O carro representa, desta forma, as barreiras físicas erguidas pelas classes mais abastadas de grandes centros urbanos como forma de proteção contra o perigo e a violência que aumentam com o crescimento das desigualdades sociais. O carro também funciona como um veículo simbólico que supostamente leva o personagem a um futuro de sucesso em Nova York. Na cidade americana, o personagem encontrará à sua disposição, segundo ele, atrizes e modelos como Julia Roberts e Naomi Campbell. A descrição que o protagonista faz das suas experiências, portanto, lembra os comerciais de veículos nos quais o homem bem-sucedido dirige carros-esporte vermelhos que atraem a atenção de mulheres deslumbrantes e o permitem viver uma vida de glamour. Também em Nova York, o protagonista afirma que encontrará dinheiro abundante, quando sua empresa se fundir ao capital internacional. Ele insiste repetidamente que "deu no rádio" que está chovendo dinheiro em Nova York, mais uma vez indicando que está seduzido pelas imagens de sucesso comumente espalhadas pela mídia, a qual tende a reproduzir o sonho americano de uma vida de consumo, comumente ligada à imagem dos Estados Unidos como símbolo de progresso e prosperidade. Além disso, o personagem enfatiza o discurso americano de linha conservadora de que o trabalho árduo leva ao sucesso: "procurei o desenvolvimento em cada instante da minha vida. Sei exatamente aonde quero chegar" (Sant'Anna, 2007, p. 10). O protagonista clama repetidamente que suas empresas e a sua fortuna são dádivas divinas, recompensas por seu trabalho constante. Seguindo esta linha de discurso religioso, o personagem denomina Nova York de "Terra Prometida", mais uma referência ao sonho americano de prosperidade e mais uma referência bíblica que se soma à alusão à história de Noé referida no título.

Tal alusão é reforçada no conto pelo dilúvio do qual o personagem tenta sem sucesso escapar. Ao dirigir para o aeroporto em busca de uma prosperidade supostamente trazida por uma chuva metafórica de 
dólares, o protagonista acaba se afogando no alagamento provocado pela chuva real que cai na cidade de São Paulo. Durante o seu percurso ao aeroporto, o personagem é progressivamente impedido de chegar ao seu destino pela realidade nada glamorosa da cidade. Os carros nacionais que se acumulam no tráfego pesado impedem a passagem de seu carro importado. Por não poder se locomover, o carro do personagem é invadido pela água suja e cheia de excrementos do rio Tietê. O conto termina com a fala do personagem sendo interrompida pela entrada de excrementos na sua boca. A interrupção da frase repetida múltiplas vezes durante a história, "está chovendo dinheiro em Nova Iorque", funciona como metáfora para a interrupção dos sonhos de consumo pela realidade subdesenvolvida da qual o personagem tenta sem sucesso se isolar. Desta forma, o conto sugere o caráter ilusório do discurso da cultura de consumo, representada pelo carro vermelho, perante as desigualdades da realidade capitalista, representada pela água da chuva e pelos excrementos. Essa realidade indica que o sonho americano do personagem é atingido não tanto graças ao seu trabalho árduo como indivíduo, mas principalmente às custas da exploração do trabalho dos muitos que nunca atingirão o status social do protagonista.

No segundo conto abordado na presente análise, intitulado "Questão estética", acompanhamos uma espécie de depoimento de uma jovem secretária sobre a importância da aparência física na vida social e profissional. A fala da personagem indica como a cultura de consumo influencia a sua visão de si mesma, dos outros e das relações profissionais e amorosas. Nesse sentido, a cultura de consumo opera de forma a reforçar divisões sociais através do estabelecimento de conexões entre estilos de vida e classes sociais. A personagem, por exemplo, categoriza pessoas com base no que vestem, calçam, no perfume que usam ou mesmo em certos aspectos do corpo: ela associa homens que calçam tênis com atletas ou adolescentes; homens maduros e bemsucedidos são associados com sapatos italianos; já aqueles que querem se fazer passar por bem-sucedidos, ela identifica pelos sapatos mocassim combinados com meias brancas "felpudinhas". Segundo a personagem, para ascender socialmente é importante parecer com a classe social visada. Nas suas palavras, "para ser vitoriosa você tem que parecer vitoriosa. A roupa que você usa é o retrato de quem se é" (Sant'Anna, 2007, p. 46). Portanto, ser vitorioso ou vitoriosa significa 
para ela atingir um status social alto que possa ser verificado através da exibição de certos bens de consumo, bem como de um certo estilo de vida, o qual inclui frequentar um bom restaurante, degustar bons vinhos e fazer viagens internacionais. Também o corpo, particularmente o corpo masculino, deve seguir um certo padrão de estética considerado sinal de sucesso. Para ela, "[barriga] é sinal de desleixo" (Sant'Anna, 2007, p. 49). Enquanto a personagem associa a um gosto refinado usar sapato italiano, saber combinar um terno com uma gravata e conhecer bons vinhos, o brega, ou o gosto das classes mais baixas é para ela sinônimo de usar cueca samba-canção de seda estampada, "se emperiquitar" como uma perua emergente e usar loção pós-barba adocicada. Desta forma, a fala da personagem indica que o gosto, conforme afirma Pierre Bourdieu em Distinction: a social critique of the judgment of taste (1984), está associado a uma maneira de ser de uma classe social. Práticas da vida cotidiana, tais como a escolha do que vestir, o cuidado com o corpo, o consumo de comidas e bebidas, codificam uma posição social expressada através dos bens que se consomem (ou não) em cada uma dessas práticas.

Nesse universo, a personagem de Sant'Anna chega a ver até a si mesma como uma mercadoria. Usando uma linguagem que remete àquela da economia capitalista, ela fala, por exemplo, da necessidade de as mulheres darem "uma investida no visual" $\mathrm{e}$ "dar um tchan na hora de falar com um o diretor ou com um cliente importante" (Sant'Anna, 2007, p. 45, grifo nosso). As mulheres, na concepção da personagem, necessitam, como os homens, exibir certos bens de consumo, mas também precisam elas mesmas se tornar mercadoria. Essa mercantilização também se expressa na afirmação da personagem de que ir para a cama com um empresário é uma boa estratégia, pois ele pode "fazer propaganda de você para os amigos". Essa busca da personagem por alcançar distinção social é guiada por imagens e ideias às quais a cultura de massas lhe expõe, pois, como ela indica: "o amor pode nascer, sim, quando você repara que o homem por quem você está interessada é bonito e pode te oferecer uma vida interessante, uma vida cheia de glamour, cheia de intensidade, viagens, uma casa grande, um lugar onde tudo parece um sonho" (Sant'Anna, 2007, p. 47).

$\mathrm{Na}$ fala da personagem citada, pode-se perceber como a vida descrita quase parece um roteiro de um comercial ou de um filme hollywoodiano. Para ela, encontrar amor se traduz em encontrar 
alguém que lhe proporcione uma vida de conforto e extravagâncias: uma vida em que, basicamente, seus sonhos de consumo se realizem.

\section{Arte e cultura popular: cultura de massas em "Cultura" e "O mundo é assim"}

Os contos "Cultura" e "O mundo é assim" lidam com a incorporação da arte e da cultura popular pela cultura de massas. A primeira narrativa em questão, "Cultura", focaliza a produção musical brasileira contemporânea. $\mathrm{O}$ conto se resume à fala de um empresário cultural que trabalha para a Secretaria de Cultura de algum município brasileiro, provavelmente, São Paulo. A fala do personagem é dirigida a uma banda com quem negocia a futura produção de um videoclipe por ele descrito como "supervanguarda", "dodecafônico", que expressaria a "estética minimalista" e a música "superpós-moderna", de uma "urbanidade tropical": "um videoclipe no centro da cidade. Vocês em frente a um daqueles prédios antigos, tocando com as crianças de rua ao redor, tá ligado?... Bem São Paulo, bem, New York, tá ligado?" (Sant'Anna, 2007, p. 101).

Tal descrição aponta para a apropriação de elementos da alta cultura pela cultura de massas, especificamente, da linguagem da vanguarda. O conto, desta forma, sugere a comodificação da alta cultura, um processo em andamento desde o final do século XIX, como indica Andreas Huyssen em After the great divide: modernism, mass culture, postmodernism (1986). Segundo Huyssen, enquanto o modernismo europeu do início do século XX procurou contestar essa comodificação através da separação entre a arte e interesses materiais, as vanguardas europeias passaram a incorporar elementos da cultura de consumo de forma crítica com vistas a reconectar a arte com o cotidiano e de protestar contra a arte enquanto instituição. As vanguardas procuraram mostrar que a arte não era algo natural ou autônomo, e, sim, uma prática circunscrita à conjuntura capitalista. Já nos anos 1950, o trabalho de artistas pop como Andy Warhol parecia confirmar de vez que a arte havia sido comodificada, dado que muitos dos artistas pop, incluindo o próprio Warhol, tinham um contato estreito com a publicidade e o desenho gráfico. Nas palavras de Huyssen, a arte pop, "mais do que qualquer outro movimento artístico precedente, desnudou o caráter de mercadoria de toda a arte contemporânea" (Huyssen, 1986, p. 149, tradução nossa). 
Em “Cultura", Sant'Anna representa essa perda de força da ideia de vanguarda, a qual parece se esgotar na medida em que passa a ser comercializada. Tal ideia é representada na própria linguagem com a qual o personagem principal do conto descreve o futuro videoclipe da promissora banda. A fala do produtor cultural indica uma concepção extremamente superficial do que significa "vanguarda", "pósmoderno", ou "minimalista", conceitos a serem vendidos, como ele mesmo indica, ao canal de televisão MTV. A superficialidade com a qual o personagem usa os termos em questão se faz evidente na falta de contextualização de tais conceitos, os quais aparecem simplesmente colocados juntos de maneira praticamente aleatória. Além disso, o uso de termos técnico-científicos como aqueles citados contrasta fortemente com a quantidade de gírias utilizadas pelo narrador e com a repetição de expressões como "tá ligado?", as quais não acrescentam muita substancialidade às suas opiniões.

O personagem também sugere que o videoclipe da banda faça uma futura apropriação superficial do conceito de antropofagia, tão caro às artes brasileiras. Como sabemos, o conceito em questão foi proposto pelo modernismo brasileiro no "Manifesto antropófago" em 1928. Nesse documento, o escritor Oswald de Andrade propunha que as artes brasileiras produzissem algo original a partir da deglutição metafórica de diversas referências culturas, nacionais e estrangeiras, passadas e contemporâneas. Tal conceito é retomado pelo movimento tropicalista nos anos 1960, cujos líderes na música foram Caetano Veloso e Gilberto Gil, e mais tarde pela Geração de 1990 da Música Popular Brasileira (Bezerra, 2003). Embora em contextos diferentes, e implementada de formas distintas, nos três casos, a ideia de antropofagia cultural surgiu como expressão de um desejo de estabelecer um diálogo com referências culturais diversas, em especial estrangeiras, no qual estas não simplesmente dominassem a cultura brasileira. No texto de Sant'Anna, o conceito de antropofagia é reduzido à reprodução de uma visão exótica do espaço brasileiro urbano, alinhada a um padrão hollywoodiano de exoticismo:

O clipe do Waltinho vai abrir com vocês assim, vestidos que nem guerrilheiros, tá ligado? Aí paf, pum, corta pras crianças de rua devorando um cadáver ... Pô, tive uma ideia do caralho: saca antropofagia? Então... tudo em preto-e-branco, tá ligado? O pessoal urbano lá do centro comendo umas coisas meio nojentas, 
assim, tipo vísceras humanas, tipo Apocalipse now. Saca Apocalipse now? (Sant'Anna, 2007, p. 103).

Desta forma, em vez de uma antropofagia cultural crítica, a apropriação do conceito em questão, tal como proposta pelo personagem, transforma o subdesenvolvimento em mercadoria "hip e cool", um espetáculo a ser consumido pelo público nacional e/ou internacional. O Waltinho mencionado na citação, segundo o protagonista, é o cineasta brasileiro Walter Salles, responsável por sucessos de bilheteria como Central do Brasil (1998), o qual projetou o cinema brasileiro no cenário internacional, tendo sido nomeado ao Oscar de melhor filme estrangeiro e de melhor atriz principal pela atuação da atriz Fernanda Montenegro, um dos ícones das telenovelas do maior conglomerado midiático do Brasil, a Rede Globo. Desde então, Walter Salles tem estado envolvido em diversas produções internacionais, tais como Diários de motocicleta (2004) e, mais recentemente, On the road (2012). A capacidade de criar sucessos internacionais e de crítica que Salles teria seria utilizada, segundo o personagem de Sant'Anna, de forma a catapultar a carreira da banda com a qual ele planeja trabalhar.

Além da direção comercialmente bem-sucedida de Walter Salles, o personagem planeja contar com o auxílio de verba do governo destinada ao incentivo à cultura. Tal verba, que a princípio deveria ser utilizada com vistas a estimular a produção cultural no país, revela-se um investimento comercial também na carreira política do governador para o qual o produtor cultural do conto trabalha, pois este chega mesmo a criar um slogan para o governo com vistas a explorar politicamente a estética da banda: "para um governo revolucionário, uma música revolucionária” (Sant'Anna, 2007, p. 103). A fala do personagem, portanto, sugere a absorção do cultural e do político pelos interesses econômicos na sociedade capitalista tardia. Desta forma, a realidade da produção cultural brasileira contemporânea é representada no conto como pós-moderna no sentido que define o teórico Fredric Jameson em Postmodernism, or, the cultural logic of late capitalism (1986). Para Jameson, o pós-modernismo é um período no qual o capitalismo se manifesta na sua forma mais pura: cada canto da vida cotidiana se encontra comodificado. A apropriação midiática que o produtor cultural do conto de Sant' Anna pretende fazer da ideia de antropofagia representaria, neste sentido, a proliferação de imagens simulacras que caracterizam o pós-moderno, segundo Jameson. Essas imagens, 
distanciadas da sua base original, se esvaziam de significado, contribuindo, assim, para tornar cada vez mais difícil a identificação das linhas que separam arte e mercadoria.

A transformação da cultura em mercadoria, no entanto, se disfarça de compromisso social com a cultura no discurso do personagem do conto em questão na medida em que ele tenta convencer a banda a tocar de graça em um projeto chamado "Música na Praça", com a desculpa de que supostamente não teria dinheiro para pagar a banda até que a verba do governo saia: "pra gente, que é artista, dinheiro é o de menos. O importante mesmo é criar uma identidade cultural pro país, acabar com esse negócio que no Brasil só tem bunda" (Sant'Anna, 2007, p. 103). O discurso do personagem se contradiz no sentido em que toma a produção artísticocultural ora como mercadoria e fonte de lucro, ora como produção independente que não deve ser "corrompida" pelo dinheiro, segundo o que lhe é conveniente. Sua fala, portanto, encapsula a conflituosa posição da arte e do artista no capitalismo tardio: entre a necessidade de depender do capital e a ética de se expressar contra a lógica daquele.

De forma semelhante à "Cultura", o conto "O mundo é assim" aborda a produção cultural nacional. No caso deste último conto, porém, o foco se dá na apropriação da cultura popular (e não da alta cultura) pela cultura de massas. Em "O mundo é assim", temos acesso à fala de uma mulher que trabalha para uma grande rede de televisão brasileira, a qual guarda semelhanças com a Rede Globo. Em sua fala, a personagem explica como funciona o mundo da televisão e por que certos tipos de programas não são adequados para este meio de comunicação. Os argumentos apresentados pela mulher têm dois pontos principais que acabam se contradizendo ao longo da sua fala, contradição esta que constitui o cerne da crítica do texto de Sant'Anna: o aspecto comercial da televisão e a suposta faceta democrática e artística deste meio de comunicação. Posicionando-se como uma mediadora entre estes dois aspectos, a personagem se apresenta como aquela que "[faz] a ponte entre as necessidades comerciais da televisão e a criação artística" (Sant'Anna, 2007, p. 84), uma autodefinição que, como veremos, é também posta em questão ao longo da fala da própria personagem.

Logo no início do relato, a personagem afirma que, na televisão, "é muito dinheiro envolvido" e, portanto, ela tem de representar os interesses da emissora, "[bancando] a executiva calculista, sem coração a cruel" (Sant'Anna, 2007, p. 84). Deixando claros os interesses financeiros 
da indústria televisa, a personagem nota que "televisão não é lugar pra Glauber Rocha" (Sant'Anna, 2007, p. 85). Em outras palavras, segundo ela, não há espaço para produções politicamente engajadas e esteticamente complexas como os filmes do cineasta brasileiro ao qual ela se refere. Na televisão cabe, nas palavras da personagem, somente o gosto da maioria, o qual é determinado por pesquisas do Ibope. Essa observação indica como os meios de comunicação de massa se apropriam de aspectos da cultura popular para assim se fazerem hegemônicos, conforme mostra o crítico Jesús Martín-Barbero (1993). Segundo ele, a cultura de massas não simplesmente manipula indivíduos a consumir uma cultura "degradada", mas, sim, incorpora aspectos da baixa cultura para assim falar a um público mais amplo. No caso particular do Brasil, por exemplo, as populares telenovelas incorporam elementos melodramáticos que Martín-Barbero identificaria como remanescentes do teatro mambembe da Idade Média.

O conto de Sant'Anna alude à popularidade do melodramático ao comparar o autor de novelas Gilberto Braga com o cineasta brasileiro anteriormente mencionado Glauber Rocha. Ao fazer essa comparação, a protagonista do conto questiona: "o que você prefere? O elogio de uma revista de cinema que ninguém lê ou milhões, eu disse milhões de pessoas, que param tudo o que estão fazendo para assistir ao seu trabalho?" (Sant'Anna, 2007, p. 88). Esta afirmação da personagem, por um lado, ressalta o potencial democrático dos meios de comunicação de massa, dado o alcance de público destes. Como ela mesma afirma, "não existe nada mais democrático, a nível de cultura, do que a televisão" (Sant'Anna, 2007, p. 85). No entanto, esse potencial é quase completamente anulado quando se leva em conta o controle de conteúdo que se dá na produção televisiva, tal como a própria personagem revela. Desta forma, se, por um lado, a fala da protagonista tenta argumentar que a televisão é um meio democrático, por outro lado, essa mesma fala revela aspectos da produção midiática que desfazem a percepção que a personagem tenta reproduzir. Isso fica evidente, sobretudo, quando ela deixa transparecer que o conteúdo do que aparece nesse meio não é simplesmente determinado pela "vontade da maioria", mas também pelos interesses comerciais de patrocinadores: "a pessoa tem todo o direito de dizer o que pensa, desde que não seja com o dinheiro dos nossos anunciantes" (Sant'Anna, 2007, p. 86). 
Segundo a personagem, dinheiro e poder influenciam não só a programação de entretenimento da televisão como também o jornalismo. Citando o exemplo de jornalistas de esquerda que querem fazer reportagens-denúncia e que protestam quando são forçados a fazer reportagens sobre questões políticas de menor consequência, a personagem observa:

Custa ir lá e fazer a matéria numa boa?: "A Câmara dos Deputados acaba de aprovar a lei que determina o investimento de $x$ por cento para os plantadores de alfafa no interior do estado". Pronto: foi lá, fez a parte dele, ganhou o salário no final do mês, férias, décimo-terceiro, seguro-saúde, tíquete de refeição, fundo de garantia... (Sant'Anna, 2007, p. 86).

Essa observação indica as limitações do engajamento político através de meios de comunicação de massa controlados por interesses privados. $\mathrm{Na}$ passagem citada, indica-se que há uma censura nos meios de comunicação de massa, a qual é talvez ainda mais perversa do que aquela imposta pelo governo ditatorial nos anos 1970, pois ela se dá de forma indireta, em troca do que deveria ser visto como direitos trabalhistas e não como moeda de compra de silêncio e conformismo.

No conto de Sant'Anna em questão, a lógica da cultura de massas, particularmente da televisão, é ainda estendida à lógica da realidade social, sugerindo-se que essas duas esferas - a do cotidiano e a da mídia - se confundem. Essa sugestão transparece na repetição insistente ao longo do conto de que "na televisão, no mundo, é assim" (Sant'Anna, 2007, p. 87). A personagem, por vezes, faz comparações entre a lógica da televisão e a do cotidiano, resumidas em clichês: "gente assim, cheia de opinião própria não dura um mês aqui na televisão, no mundo"; "na televisão, no mundo, é assim: eu trabalho e os outros ficam com a fama"; "na televisão e no mundo é assim: só há lugar para os vencedores, do Ibope e da vida" (Sant'Anna, 2007, p. 85-88). Nessas três instâncias, é a lógica do poder capitalista que domina: do controle da participação no debate público ao discurso sobre o que significa ser vitorioso, passando pela exploração do trabalho de outrem em benefício próprio. Ao comparar a vida cotidiana à indústria da televisão, a personagem sugere que uma reproduz a lógica da outra, ou que "a vida imita a arte (da TV)", como diz o ditado, talvez porque as duas estejam determinadas pela mesma lógica capitalista que molda a percepção da personagem, tal como delineada nas citações comparativas 
mencionadas neste parágrafo. Desta forma, o conto complementa o próprio título: "O mundo é assim", ou seja, "assim como a mídia".

A lógica capitalista e a visão pragmática que a personagem aplica no trabalho é transferida por ela à sua vida cotidiana com o marido, de acordo com o que ela descreve. Segundo a protagonista, o marido casouse com ela por interesse na sua condição financeira, o qual ela não condena, pois acredita que "pra casar com uma mulher mais velha, assumindo os filhos de outro cara, é normal que haja um certo interesse" (Sant'Anna, 2007, p. 87). O marido, na sua descrição, lhe serve de babá e secretária doméstica, uma troca que para ela lhe cai bem, pois não está interessada em uma relação amorosa. Poder, marido, amante, sexo são coisas que ela percebe como mercadorias às quais tem acesso desde que consiga manter o emprego, desde que o Ibope continue alto. Para tanto, ela faz o que for necessário para agradar à empresa para a qual trabalha, corroborando em suas ações o que descreve como sendo a lógica interna da televisão, como vimos anteriormente. Neste sentido, os interesses individualistas da personagem reproduzem os interesses privados que ela defende em seu trabalho na televisão, sem muita consideração por responsabilidades políticas ou artísticas. A personagem se converte, neste sentido, não na ponte entre a arte a mercadoria como ela afirma ser no princípio do conto, mas, sim, na defensora de interesses pragmáticos e individualistas de cunho capitalista.

Recompensas financeiras é o que ela afirma buscar também para aqueles que a procuram na emissora, transformando, nas palavras dela, "jovens metidos a Glauber Rocha" em sucessos comerciais. Em seu discurso, a personagem deixa mais uma vez transparecer que a lógica do mercado afeta a produção da arte ao notar que "hoje em dia não existem mais gênios" e que por isso ela incentiva aqueles que estão começando a "colaborar com os interesses da emissora" para em troca serem recompensados com fama e dinheiro (Sant'Anna, 2007, p. 88).

\section{Reflexões finais}

A cultura de consumo é representada nos quatro contos analisados como uma presença intrínseca nas mais banais atividades cotidianas da vida brasileira de indivíduos de classes sociais diversas. Tal senso de banalidade é reforçado pela linguagem dos contos, especialmente no caso de "Questão estética" e "O mundo é assim", narrativas cuja tônica 
é marcadamente oral e coloquial, contendo repetições, reformulações e divagações. Nos quatro relatos, a ausência de narradores e a impressão de que os personagens falam diretamente ao leitor (ou a alguém em cuja posição o mesmo é colocado, como no caso de "Cultura"), juntamente com a linguagem oral que mais parece uma transcrição da fala ou um script, apelam para uma espécie de sensibilidade midiática do leitor. Assim, este é convidado a visualizar o que lê como se assistisse a uma cena captada por uma câmera.

Esse diálogo com a cultura de massas gera, no caso dos contos analisados, textos de fácil acesso e de leitura rápida, que se diferenciam, desta forma, de uma tradição de incorporação de elementos da cultura de massas e da cultura de consumo com vistas a criar distanciamento através de uma estética da dificuldade, a qual se contraporia à linguagem fácil e afirmativa da cultura de massas. Longe de constituir uma afirmação da cultura de consumo, os contos revelam um profundo questionamento dessa cultura. No caso de "O importado vermelho de Noé", o questionamento da mentalidade consumista do personagem se dá através do contraste entre a fala deste, a qual afirma um discurso de sucesso individual, e a realidade que o cerca, a qual põe em xeque o preço social de tal sucesso. Já no caso de "Questão estética", enquanto a personagem afirma que "não é o dinheiro desses homens que me atrai", ou que "tudo bem, beleza não é o mais importante", o seu discurso sobre beleza e dinheiro, como vimos, contradiz diretamente tais afirmações. Indícios de contradição também são responsáveis por desfazer o discurso dos protagonistas de "Cultura" e "O mundo é assim", em suas observações que tentam em vão conciliar compromisso social e interesse comercial na produção artística contemporânea. Nos quatro contos, o questionamento das visões de mundo dos personagens também se nota na aparente superficialidade dos seus argumentos e na irônica repetição de clichês.

Os contos de Sant'Anna aqui analisados articulam uma crítica da presença da cultura de consumo e da cultura de massas no cotidiano brasileiro atual no sentido que propõe Henri Lefebvre em Critique of everyday life. Para o crítico em questão, "o mundo humano não está definido simplesmente pelo histórico, pelo cultural, pela totalidade ou pela sociedade como um todo, ou por estruturas ideológicas e políticas. Ele está definido por esse nível intermediário e mediador: a vida cotidiana" (Lefevbre, 2002, p. 45, tradução nossa, grifo do original). Ao 
privilegiar o cotidiano brasileiro atual, adotando a linguagem de uma cultura de massas que é parte tão forte dele, os contos de Sant'Anna, desta forma, representam a cultura de consumo não como uma força que opera em um nível abstrato sobre sujeitos tomados como parte de uma coletividade homogênea, mas, sim, como uma força que se entranha nas miudezas do cotidiano de indivíduos com variados backgrounds.

\section{Referências}

ADORNO, Theodor W. (1990). Cultural industry redonsidered. In: ALEXANDER, Jeffrey C.; SEIDMAN, Steven. Culture and society: contemporary debates. Cambridge.

BEZERRA, Ligia Cristine de Morais (2003). Tropicalismos na música popular brasileira: um olhar interdiscursivo sobre a geração de 1990. Dissertação (Mestrado em Linguística) - Universidade Federal do Ceará (UFC), Fortaleza.

BOURDIEU, Pierre (1984). Distinction: a social critique of the judgment of taste. Tradução de Richard Nice. Cambridge: Harvard University Press.

CANCLINI, Néstor García (2001). Consumers as citizens: globalization and multicultural conflicts. Tradução de George Yúdice. Minneapolis: University of Minnesota Press.

FELSKI, Rita (2000). The invention of everyday life. New Formations, n. 39, p. 15-31. HUYSSEN, Andreas (1986). After the great divide: modernism, mass culture, postmodernism. Bloomington: Indiana University Press.

JAMESON, Fredric (1991). Postmodernism, or the cultural logic of late capitalism. Durham: Duke University Press.

LEFEBVRE, Henri (2002). Critique of everyday life. Tradução de John Moore. London: Verso. v. 2 (Foundations for a sociology of the everyday).

MARTÍN-BARBERO, Jesús (1993). Communication, culture and hegemony: from the media to mediations. Tradução de Elizabeth Fox e Robert A. White. London: Sage Publications.

MORIN, Edgar (1967). La indústria cultural. Tradução de Susana Constante. In: ADORNO, Theodor W.; MORIN, Edgard. La indústria cultural. Buenos Aires: Galera.

SALLES, Walter (1998). Central do Brasil. Le Studio Canal.

SALLES, Walter (2004). Diários de motocicleta. FilmFour. 
SALLES, Walter. (2012) On the road. American Zoetrope.

SANT'ANNA, André (2007). Sexo e amizade. São Paulo: Companhia das Letras.

SANTOS, Lidia (2006). Tropical kitsch: media in Latin American literature and art. Tradução de Elisabeth Enenbach. Princeton: Markus Weiner.

Recebido em junho de 2014.

Aprovado em outubro de 2014.

\section{resumo/abstract}

\section{Cenas cotidianas: cultura de consumo e mídia em contos de André Sant'Anna}

Ligia Bezerra

Este artigo propõe uma análise da representação da cultura de massas e da cultura de consumo em relatos de Sexo e amizade, do escritor brasileiro André Sant'Anna. Situamos estes relatos no fluxo de um extenso diálogo da literatura brasileira com a cultura de massas, o qual tem se efetivado desde o início do século XX e através do qual a literatura brasileira tem, com frequência, elaborado uma crítica à cultura de consumo. Argumentamos que, nos textos em questão, Sant'Anna representa a cultura de consumo como uma força intrinsecamente presente nas relações sociais e na forma de pensar dos personagens. Afastando-se do que Lidia Santos chama de estética da dificuldade, uma marca comum da literatura brasileira que se engaja com esse tema entre os anos 1960 e 1980. André Sant'Anna articula uma crítica da presença da cultura de consumo no cotidiano brasileiro a partir de uma linguagem predominantemente midiática e acessível, retratando indivíduos oriundos de diferentes classes sociais.

Palavras-chave: consumo, cotidiano, cultura de massas, André Sant'Anna.

\section{Everyday scenes: consumer culture and media in André Sant'Anna's short stories}

Ligia Bezerra

This article presents an analysis of the representation of mass culture and consumer culture in relatos (stories) from André Sant'Anna's Sexo e amizade. I analyze the stories in question within the context of Brazilian literature's 
extensive dialogue with mass culture that has been in place since the beginning of the twentieth century, and which has often produced critiques of consumer culture. I argue that, in the stories under study, Sant'Anna represents consumer culture as a force that is intrinsic to characters' social relations and conceptualizations of reality. He articulates a critique of consumer culture's presence in Brazilian everyday life that departs from what Lidia Santos calls an aesthetic of difficulty, which marked Brazilian literature's approach to mass culture between the 1960s and the 1980s. This critique is conveyed through the use of language that is predominantly accessible and mediatic and through the depiction of individuals from different social classes.

Palavras-chave: consumption, everyday life, mass culture, André Sant'Anna. 